Assiut Scientific Nursing Journal

http://asnj.journals.ekb.eg

http://www.arabimpactfactor.com

DOI: $10.21608 / A S N J .2021 .96789 .1237$

\title{
Effect of Mobile Application Intervention on Health Literacy Regarding Antenatal Care among Primigravida Women during the COVID-19 Pandemic
}

\author{
Sabah Ramadan Hussein Ahmed ${ }^{1}$, Hala Abd Elfattah Ali $^{2}$, Nagat Salah Shalaby ${ }^{3}$, Reda T. A. Abou Elazab ${ }^{4}$, \\ Asmaa Elsayed Farid Amr ${ }^{5}$ \& Gehan Ahmed Mohmed Elbahlowan ${ }^{6}$ \\ 1. Assistant Professor of Maternal \& Newborn Health Nursing, Faculty of Nursing, Helwan University, Egypt. \\ 2. Assistant Professor of Women's Health \& Midwifery Nursing, Faculty of Nursing, Kafr El Sheikh University, Egypt. \\ 3. Assistant Professor of Maternity, Gynecology, \& Obstetrics Nursing, Faculty of Nursing, Port Said University, Egypt. \\ ${ }^{4 .}$ Lecturer of Mental Health and psychiatric Nursing, Faculty of Nursing, Port Said University, Egypt. \\ ${ }^{5 .}$ Lecturer of Family and Community Health Nursing, Faculty of Nursing, Menoufia University, Egypt. \\ ${ }^{6 .}$ Lecture of Obstetrics \& Gynecology, Faculty of Nursing Port Said University, Egypt.
}

\begin{abstract}
Background: Mobile application is an innovative opportunity for pregnancy self-care and health literacy is crucial for primigravida's pregnancy self-care. Aim: This study aimed to examine the effect of mobile application intervention on health literacy regarding antenatal care among primigravida women during the COVID-19 pandemic. In addition to assess the satisfaction level of primigravida toward mobile application utilization. Methods: A quasiexperimental design (pretest/posttest for one group) was adopted. A purposive sample of 90 primigravida women was recruited and allocated to study group. The current study was conducted at outpatient antenatal clinic in Maternity hospital, Port Said Governorate, Egypt. Three tools were used for data collection: Structured interviewing questionnaire schedule, Maternal Health Literacy and Pregnancy (MHLAP) and satisfaction level tool. Results: There were highly statistically significant differences among primigravida women on total score of health literacy regarding antenatal care and practice pre and post mobile application intervention . Fortunately, there were $86.7 \%$ of primigravida were satisfied toward mobile app utilization while only $13.3 \%$ of primigravida were dissatisfied. Conclusion: Mobile application intervention is effective on health literacy regarding antenatal care among primigravida women during the COVID -19 pandemic. Recommendation: Utilizing mobile application intervention on health literacy regarding antenatal care among pregnant women during the COVID -19 pandemic by nurses should be encouraged.
\end{abstract}

\section{Keywords: Antenatal care, COVID -19 pandemic, Health literacy, Mobile application \& Primigravida Women}

\section{Introduction}

Pregnancy is an important phase in the women'life that require more attention to women as prepare themselves to a new status as mothers. Maternal and child health center -based health promotion resources to help pregnant women especially primigraphida in adopting a healthy lifestyle are important. Now a day due to COVID -19 pandemic, women are using mobile apps in order to access health information during antenatal period(Özkan et al.,2018).

Smartphone possession and application usage are $81 \%$ in Australia, and $97 \%$ of the mobile customers matured between age group 18 and 34 years. In 2019, mobile phones were the most public device used to contact the internet which constitute about $87 \%$, followed by using of a laptop represented about $69 \%$, and then 56\% used tablets. The internet users contact the internet for health service area constituted about $46 \%$ according to the newest Australian report. It has been appraised that up to 1 in each 4 Australians used smartphones to contact the health-related apps to sustenance healthy activities (Musgrave, et al., 2020).

Mobile application is a recent method of endorsing excellence of treatment outcome, nursing care, dropping therapeutic expenses and the requirement for appointments, participation of patient and family in choice assembly, and vigilant patient specialist care via forms of technologies altogether (Schlottmann, et al., 2019). The mobile is considered the greatest widespread announcement device used in the advanced states due to its cost-efficiency and good availability. Studies showed that mobile accessing is an alternate to personal appointments for obtaining care and mark performance variations that it is an active standard to simplify the treatment of longlasting diseases as well as upsurge patients' capability of self-care by contribution therapeutic care (Mohamed \& Fashafsheh, 2019)

Recently, mobile skills are broadly applied in the establishment facilities of the pregnancy care, promoting from speedy advance of the information 
communication technology (ICT) and worldwide contact to these skills. Due to the growing possession mobile phones frequency, a great numeral of mobile applications on health issues are established and are fixed by customers. Furthermore, rapid contact to healthiness data, mobile applications can advance communications through the well-being upkeep organization. Likewise various applications can encourage healthiness performances for instance keeping adequate bodily movement and partaking a well nourishment (Chan \& Chen, 2019).

Health literacy (HL) is the grade to which persons have the ability to recognize, understand, besides usage data and facilities to inform healthiness-related choices and actions for themselves and others (Santana, et al., 2021). The pregnant woman HL is operative in getting precise and appropriate upkeep facilities as of healthiness organizations. Maternal HL is definite information and distinct public services which used in diagnosing risk factors of the pregnancy, promoting a healthy lifestyle including appropriate nutrition needed during this period and improving the pregnancy outcomes through utilizing the importance of pregnancy care. HL is actual significant in pregnant women's thoughtful of antenatal jeopardies. Antenatal care if effectively applied, can be an operative interference to recover pregnancy, together with decreasing baby and mother death owing to pregnancy and childbirth, besides particularly death perinatally (Solhi, et al., 2019 \&

Karamolahi, et al., 2021).

Utilization of mobile apps is evident and possible for antenatal upkeep. Pregnant women with complications require further care also pregnant women without complications can become complicated sudden. The encounter isn't in scheming the software, the actual encounter lies in keeping fit health care workers and pregnant women to practice the applications. The mobile nature of telehealth delivers a chance to develop contact to pregnancy and childbirth facilities, in addition, might support to alleviate adverse health outcomes for pregnant women. There is evidence that telehealth in maternity is possible and valuable (Westwood, 2021).

There are $50 \%$ of pregnant women have insufficient $\mathrm{HL}$ in addition insufficient HL averts appropriate recognition of health messages and information. Recently, more than seventy five percent of the pregnant women utilized mobile applications associated pregnancy throughout the COVID-19 pandemic. Pregnancy period needs continuousness of upkeep and therapy. Throughout the pandemic progression, mobile applications are utilized to encounter the requirement for health care all over the world, also services in this extent are advanced (Şat \& Sözbir, 2021)
Health literacy acting a vital part throughout pregnancy, by way of the woman's well-being performance effects woman and her baby health together. According to the researcher's information, no inclusive impression on evidence of the HL of primigravida during pregnancy exists. The studies and review reported that randomized controlled trials and the interventions to advance HL in the pregnant women are rare or not exist. This is an important in the light of HL levels found among the pregnant women. Health care provider especially midwife nurse plays a crucial role in this framework, because primigravida with inadequate HL depend on them as bases of health data (Nawabi, et al., 2021).

A pregnant woman's education is an important determinants of decreasing neonatal mortality. One of the responsibilities of the nurse is to provide detailed, and appropriate information to the pregnant women during this critical period. This is because health information help empower pregnant women to protect their health and their unborn child that of their unborn child. So, the nursing intervention through the use of mobile application may promote a reliable, time-saving and also, cost effective approach to delivery of quality healthcare during COVID-19 pandemic (Whitaker, et al.,2016)

\section{Significance of the study}

Every two minutes, one of the pregnant woman dies from complications of pregnancy or childbirth in the world. Globally, 400 per 100,000 live births, however in Eygpt, the maternal mortality ratio is 37 per 100,000 live births. This is significantly related to ignorance about expected care and lack of health information during antenatal period (Farzi, et al., 2019).

According the latest statistics there are 270,000 of pregnant women have infected with COVID-19, and 2,600 of them have died from the virus in america, Mexico and Colombia. COVID-19 became the leading cause of maternal deaths in 2021.In arab emirates, there was $37 \%$ death among pregnant women due to influenza and COVID-19 (Hazari, et al., 2021).In Egypt, there is lack of statistics regarding pregnant women death related to pandemic disease.

Study done by $\mathbf{W u}$, et al., (2020) indicated that, the pregnant women espicially primigraphida should follow antenatal visit schaduale as they need more access to the basic health information on the safe motherhood and have the right to receive quality healthcare based on their need. But due to COVID19 pandemic, one fifth of pregnant women were frightened of any form of consultation at a hospital, whereas over forty percent be scared in-hospital prenatal appointments. Furthermore, more than fifty percent decided to withdraw their in-hospital prenatal 
care appointments and postponed their visits. These behaviors and attitudes show that pregnant women were worried and bothered about possible infection in the hospital environment . As the COVID-19 infection speedily spread all over the world, growing death rate. As portion of persistent worldwide and due to COVID-19 is measured as pandemic in Egypt, the evolving pandemic coronavirus is considered a definite and unusual phenomenon (Ahmed, et al., 2021). So that, there is a crucial requirement to improve Primigravida HL using Mobile Application Intervention.

Assessing primigravida HL is very important to determine gaps, weakness and strength to eliminate efforts, facilitate the outbreak management of COVID-19 in Egypt and control of the disease transmission among Primigravida. In view of the dilemma mentioned above and the fear of some other strangers from hospital visits, mobile application might be a superior choice for primigravida during this pandemic. Concerning the high position of HL of primigravida besides the facility of applications with information transmission in addition to prosperity of contact to keep fit resources at any time during daytime and night (LoBiondo-Wood \& Haber, 2018).

Nevertheless, there are no a lot of studies about the effect of mobile application intervention on HL regarding antenatal care among primigravida women during the COVID-19 pandemic in Egypt especially Porsaid. So, the current study was carried out in order to examine the effect of the Mobil application to improve $\mathrm{HL}$ regarding antenatal care among primigravida women during COVID -19

Operational definition.

Antenatal care: It is defined as the care received to the pregnant woman during the period of pregnancy in order to confirm that woman and unborn fetus continue pregnancy and childbirth.

COVID-19 Pandemic: it is defined as an infectious disease caused by novel coronavirus disease outbreak, it is a public health emergency problem of international concern it was described as a pandemic.

Health Literacy: it is the ability to gain, read, know, and use healthcare information to make appropriate decisions and also, follow instructions for treatment.

Mobile application: It is defined as the use of mobile phones and wireless technology such as text messaging, apps, and also, video messaging in order to support the achievement of health objectives .

Primigraphida women: Woman who is pregnant for the first time

Aim of the study:

The current study aimed to examine effect of mobile application intervention on health literacy regarding antenatal care among primigravida women during the COVID-19 pandemic. In addition to assess the satisfaction level of primigravida toward mobile application utilization.

\section{Research hypotheses}

H.1. Primigravida women who use mobile application intervention will experience high score level of health Literacy regarding antenatal care after intervention than pre intervention.

H.2. Primigravida women who use mobile application intervention will experience high score level of health practice regarding antenatal care after intervention than pre intervention.

H.3. There is a difference in score level of MHLAP before and after mobile application intervention.

H.4. Primigravida women who use mobile application intervention will experience high score of satisfaction level after intervention.

\section{Subjects \& Methods Research design}

A quasi-experimental design (one group pretest/posttest) was used to test the proposed hypotheses.

\section{Research setting}

This study was conducted at Outpatient Antenatal Clinic in portsaid Maternity hospital, Port Said Governorate, Egypt. The care is provided by the nurse as doctor's order. The primigravida's admission rate was five to eight per day. Services provided to the subjects are completely free. The areas served by the hospital are Port Said city and its neighboring villages. The establishment at three days per week (Saturday, Monday and Wednesday). Those days were the Outpatient Antenatal Clinic follow-up. This hospital is affiliated to the Ministry of Health and Universal Health Insurance. The Outpatient Antenatal Clinic placed in the first floor of hospital and consisted of 2 rooms, each of them includes one bed. According to the statistical department of Port Said Maternity hospital, the total annual admission to Outpatient Antenatal Clinic is approximately 2000 primigravida.

\section{Sample}

A purposive sample of 90 primigravida was recruited according to the following inclusion criteria: primigravida who were aged between eighteen and forty five years, had first time pregnancy, their gestational age from six to twelve weeks, had reading and writing literacy, had no primary and chronic disease, had not medical training, used a mobile phone with system Android or iPhone, iPad, iPod touch or Mac also the capability to connect the WhatsApp, the capability to utilize and practice with mobile application, absence of involvement in joining in a pregnancy care training program, interest and 
accept to participate in the study. While, the exclusion criteria included: Primigravida who refusal to endure contributing in the current study or not utilize the training application will be excluded from the study.

\section{Sample size}

Based on data from the literature (Karamolahi et al., 2021), considering the level of significance at 5\%, and the power of study at $80 \%$, sample size can be calculated through the following:

$\mathrm{n}=\left[\left(\mathrm{Z}_{\alpha / 2}+\mathrm{Z}_{\beta}\right)^{2} \times\left\{2(\mathrm{SD})^{2}\right\}\right] /$ (mean difference between the two groups) ${ }^{2}$

where

$\mathrm{SD}=$ mean standard deviation

$\mathrm{Z}_{\alpha / 2}$ : This depends on the level of significance, for 5\% this is 1.96

$Z_{\beta}$ : This depends on the power, for $80 \%$ this is 0.84

As a result,

$\mathrm{n}=\left[(1.96+0.84)^{2} \times\left\{2(6.31)^{2}\right\}\right] /(2.64)^{2}=89.6$

so, the sample size required for this study is 90 pregnant women.

Sample recruitment and group allocation

A ninety of primigravida was recruited in one group that evaluated before and after intervention.

\section{Tools and technique of data collection:}

Data relevant to this study were collected using three tools as structured interviewing questionnaire schedule, Maternal Health Literacy and Pregnancy (MHLAP) and satisfaction level tool.

Tool (1) :Structured interviewing questionnaire schedule:

This questionaire was developed by the researchers after reviewing the associated literatures, and consists of three main sections: a. personal background data: This section included questions about code, age, residence, level of education, and occupation; $\mathbf{b}$. present obstetrical history: Involves data related to gestational age.

Tool (2): The Maternal Health Literacy and Pregnancy (MHLAP) questionaire

The MHLAP questionnaire is developed by Mojoyinola, 2016 in order to assess maternal health during pregnancy. it included twenty items about antenatal care. The maternal HL scores ranges from twenty to one hundred. The items of the questionnaire are depends on five-options Likert scale that classified its score as the following: Completely Agree $=$ five, Agree $=$ four, No idea $=$ three, Disagree =two, and Completely Disagree $=$ one. A higher score shows more HL.

Tool (3): Pregnant women' practice questionnaire: This tool developed by the researchers to assess primigraphida women practice as Weight Management, Gestational Diabetes Mellitus Control,
Identify Risk Behaviors, Know Danger Signs During Pregnancy, ......etc.

Tool (4): Questionnaire on Satisfaction Level

A questionnaire on satisfaction level was adopted from (Melin, et al., 2020 \& Lire, et al., 2021). It was used to assess satisfaction level on mobile app intervention on $\mathrm{HL}$ among primigravida. It included 6 items, with each item including a five-point Likert scale that ranging from $1=$ 'strongly dissatisfied' to $5=$ 'strongly satisfied'. Hence the obtainable score is $6-30$ and the score was converted into percentage and interpreted as follows. Level of satisfaction scoring system: The demarcation threshold formula can be calculated as (total highest score-total lowest score) $/ 2+$ total lowest score) which was used to set cut points for the satisfaction level. Those women who responded to satisfaction items at or above threshold cut point were classified as 'satisfied', while those who responded below threshold cut limit were classified as 'not satisfied'.

Questionnaire included questions as: What did you think about using the mobile app?. The questionnaire included general statements about, the usability of and willingness to recommend the mobile app (Figure 1).

\begin{tabular}{|c|c|c|c|c|c|}
\hline \multicolumn{6}{|c|}{ What did you think about using the health app? } \\
\hline & $\begin{array}{l}\text { Strongly } \\
\text { disagree }\end{array}$ & & & & $\begin{array}{l}\text { Strongly } \\
\text { agree }\end{array}$ \\
\hline It was easyy to use & 0 & 0 & 0 & 0 & 0 \\
\hline It was good to use & 0 & 0 & 0 & 0 & 0 \\
\hline $\begin{array}{l}\text { The time spent using it has } \\
\text { been acceptable }\end{array}$ & O & 0 & 0 & 0 & 0 \\
\hline $\begin{array}{l}\text { It has been difficult to } \\
\text { remember to use it }\end{array}$ & 0 & 0 & O & 0 & 0 \\
\hline $\begin{array}{l}\text { The introduction of how to } \\
\text { use it was sufficient }\end{array}$ & 0 & 0 & 0 & 0 & 0 \\
\hline It was too time consuming & 0 & 0 & 0 & 0 & 0 \\
\hline
\end{tabular}

Figure (1): Screenshot of Web-based Mobile app Tool validity Satisfaction Questionnaire.

The content validity of the tools developed by the researchers, the structured interviewing questionnaire schedule, was tested and confirmed by three scholastic nursing specialists in the field of maternity nursing. The tool was validated for clarity, relevance, and completeness of its contents. Accordingly, the recommended modifications were performed. 


\section{Tool reliability}

The reliability of the proposed tools was tested using Cronbach's alpha coefficient test. For the structured interviewing questionnaire schedule, Cronbach's alpha of 0.89 showed a strong, positive correlation between the tool's items. While test-retest reliability of the MHLAP was 0.95 (Karamolahi, et al., 2021). The reliability of the satisfaction-related questions was checked using Cronbach's alpha (0.92) (Lire, et al., 2021).

\section{Ethical consideration}

Informed consent was obtained from each primigravida who accepted to participate in the study after explanation of the aim of the study and its significance. Likewise, the researchers emphasized that participation in the study is entirely voluntary, and primigravida women were reassured that they had the right to withdraw from the study at any time without having to offer justifications. Anonymity and confidentiality were assured through coding the data.

\section{Pilot study}

A pilot study was done on $10 \%$ of the pre-determined sample size ( 9 primigravida) who met the selection criteria. It aimed to assess the feasibility of the study process as well as, the clarity, relevance, and applicability of the study tools. Based on the results of the pilot study, no problems were found that interfere with the data collection process and minor modifications were performed in the tools. The participants in the pilot study were excluded from the main study sample.

\section{Procedure}

Data were collected within a period of five months from the beginning of March 2021 to the end of July 2021. The researchers visited the study setting three days a week from 9:00 am to 3:00 pm. The study was conducted through: preparation, interview and assessment, implementation, and evaluation.

Preparation for the study: A thorough review of related literature has been done to construct data collection tools. Also, an official permission to conduct the study was obtained from concerned authorities (i.e., directors of Portsaid Maternity hospital).

Interview and assessment: After enrollment, the researchers hold an individual interview with each primigravida woman to obtain data related to personal background data, present obstetrical history through using the structured interviewing questionnaire schedule. The questions were asked in Arabic and the responses were documented by researchers. In addition, primigravida woman started at the Antenatal Outpatient Clinic at Port Said Maternity hospital, to choose sample and take their mobiles numbers, then complete the study and following primigravida women through WhatsApp. The interview and assessment were carried out for all primigravida women in one group. The time taken to complete this assessment was about 15-20 minutes.

\section{Implementation:}

The mobile application, built on the MHLAP questionnaire items (The body deviations and adaptations throughout pregnancy, the fetal growth, care of pregnancy, examinations, vaccinations, nourishment, supplements taking, particular hygiene, employment, transportable, relaxation, bodybuilding, sexual activity, taking medicine, pregnancy warning signs, neonatal upkeep, neonatal warning, bathing and breastfeeding, signs, taking vitamin, baby position, and coverage) was installed on the smartphones of primigravida. The primigravida was trained on how to use the application. One week after application installation on the primigravida mobile, probable questions and any difficulties in utilizing application were answered throughout the mobile call. Formerly, every week, primigravida were reminded about utilizing application through SMS, the contact numbers of researchers was given to the primigravida in order to contact the researchers if primigravida had any questions about the application. After eight weeks, the MHLAP was completed by the researchers to primigravida.

The mobile app is developed by Romman Smart Applications LLC. The name of mobile app is "You and Pregnancy" in Arabic language. Application of you and pregnancy is the first and unique application in the Arab world about the stages of pregnancy with all its details in its three stages, with all the daily and weekly developments of mother and fetus care. The primigravida can use current app information with or without internet connection. Through this application, primigravida will live the stages of pregnancy in all its beautiful details, and primigravida will get adequate answers to all her questions about pregnancy, from the latest studies provided by the largest hospitals and international medical universities on maternal and fetal care.

\section{Primigravida will get to know through this application:}

Symptoms and signs of the pregnancy as nausea, vomiting, dizziness, , water retention in the body, fatigue and how to deal with it. Nutrition needed during this period. Pregnancy problems that pregnant women will go through at each stage and how to solve them. The possibility of miscarriage and how to avoid it. Examinations to be performed at all stages of pregnancy. Labor symptoms. Sexual relationship during pregnancy and beyond. Child's development at all stages. The application includes pregnant women and pregnancy. Daily developments of pregnancy. Weekly pregnancy progression. The baby's weekly pregnancy progression. Calculate the 
birth day. Calculate the ovulation day. Monitor the child's movement to ensure baby's safety and activity. Frequently asked questions about pregnancy tips and music for pregnant women and the child (Figure 2).
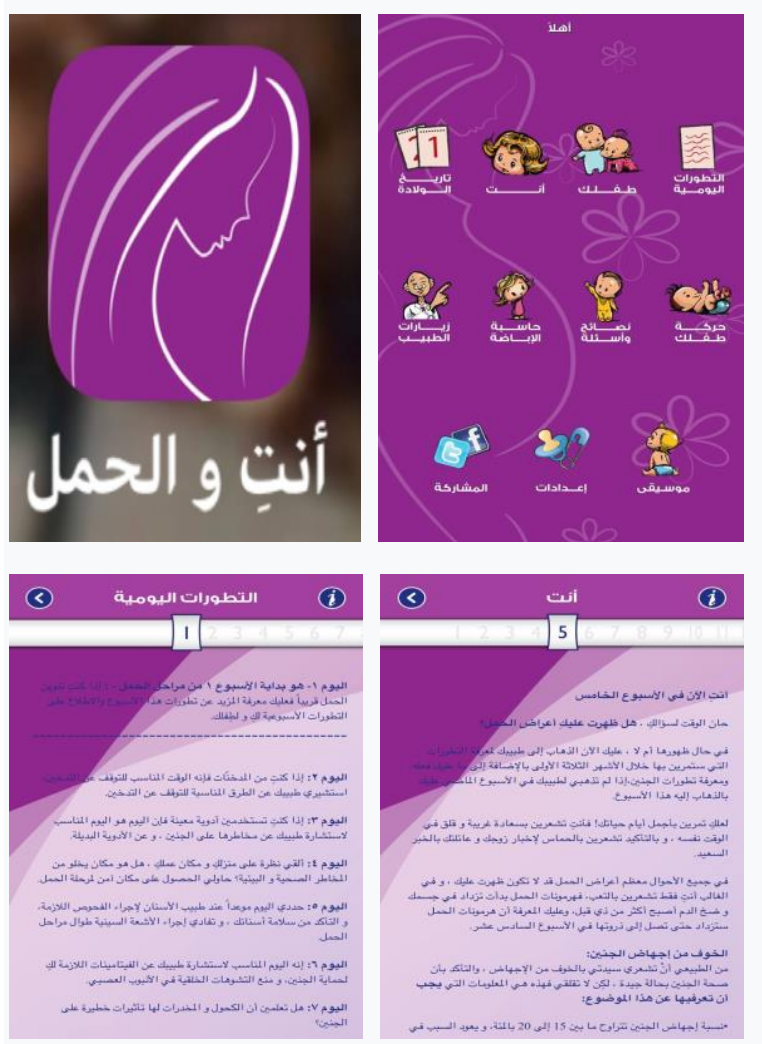
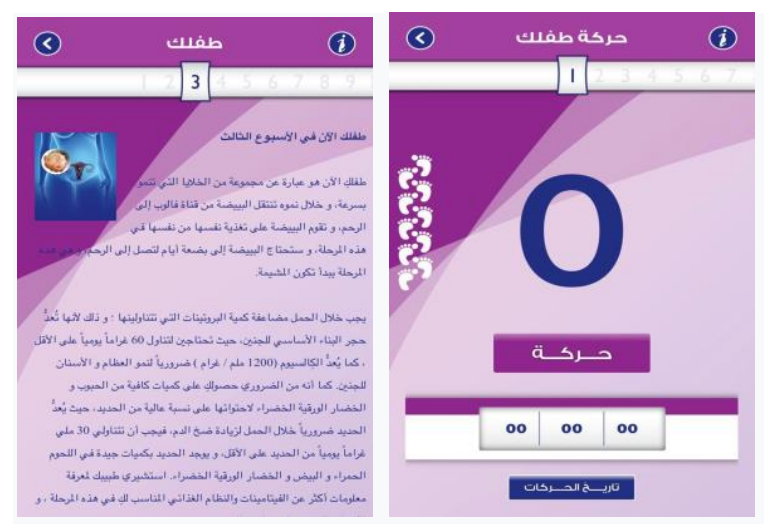

Figure (2): Screenshots of mobile app contents

Evaluation: The researchers assess the level of MHLAP questionnaire two points of time: Baseline that before intervention and eight weeks later after performing the proposed intervention. Either MHLAP questionnaire and satisfaction level were evaluated.

\section{Statistical analysis}

All statistical analyses were performed using SPSS for windows version 20.0 (SPSS, Chicago, IL). Continuous data were expressed in mean \pm standard deviation (SD). Categorical data were expressed in number and percentage. The Student's t test was used for comparison between two variables with the continuous data. Chi-square test was used for comparison of the variables with categorical data. Statistical significance was fixed at $\mathrm{p}<0.05$.

\section{Results:}

Table (1): Socio-Demographic characteristics among the studied primigravida women $(n=90)$

\begin{tabular}{|c|c|c|}
\hline Age & & \\
\hline $\begin{array}{l}18-<25 \\
25-<35 \\
35-45\end{array}$ & $\begin{array}{l}30 \\
24 \\
36\end{array}$ & $\begin{array}{l}33.3 \\
26.7 \\
40.0\end{array}$ \\
\hline Mean \pm SD & \multicolumn{2}{|c|}{$29.2 \pm 6.3$} \\
\hline \multicolumn{3}{|l|}{ Education } \\
\hline $\begin{array}{l}\text { Basic } \\
\text { Intermediate } \\
\text { High }\end{array}$ & $\begin{array}{c}4 \\
16 \\
70\end{array}$ & $\begin{array}{c}4.4 \\
17.8 \\
77.8\end{array}$ \\
\hline \multicolumn{3}{|l|}{ Job-status } \\
\hline $\begin{array}{l}\text { Housewife } \\
\text { Working }\end{array}$ & $\begin{array}{l}28 \\
62\end{array}$ & $\begin{array}{l}31.1 \\
68.9\end{array}$ \\
\hline \multicolumn{3}{|l|}{ Residence } \\
\hline $\begin{array}{l}\text { Rural } \\
\text { Urban }\end{array}$ & $\begin{array}{l}22 \\
68\end{array}$ & $\begin{array}{l}24.4 \\
75.6\end{array}$ \\
\hline \multicolumn{3}{|l|}{ Income } \\
\hline $\begin{array}{l}\text { Insufficient } \\
\text { Sufficient } \\
\end{array}$ & $\begin{array}{l}77 \\
13 \\
\end{array}$ & $\begin{array}{l}85.6 \\
14.4 \\
\end{array}$ \\
\hline \multicolumn{3}{|c|}{ Weeks of gestation } \\
\hline $\begin{array}{l}6-8 \\
9-10 \\
11-12\end{array}$ & $\begin{array}{l}23 \\
40 \\
27\end{array}$ & $\begin{array}{l}25.6 \\
44.4 \\
30.0\end{array}$ \\
\hline Mean \pm SD & \multicolumn{2}{|c|}{$9.6 \pm 1.2$} \\
\hline
\end{tabular}


Table (2):Effect of mobile application on health literacy levels regarding antenatal care among primigraphida women before and after the intervention $(\mathbf{n}=90)$

\begin{tabular}{|c|c|c|c|c|c|c|c|c|c|c|c|c|c|c|c|c|c|c|c|c|c|c|}
\hline & \multicolumn{2}{|c|}{$\begin{array}{c}\text { Completely } \\
\text { agree }\end{array}$} & \multicolumn{2}{|c|}{ Agree } & \multicolumn{2}{|c|}{ Uncertain } & \multicolumn{2}{|c|}{ Disagree } & \multicolumn{2}{|c|}{$\begin{array}{r}\text { Completely } \\
\text { disagree }\end{array}$} & \multicolumn{2}{|c|}{$\begin{array}{c}\text { Completely } \\
\text { agree }\end{array}$} & \multicolumn{2}{|c|}{ Agree } & \multicolumn{2}{|c|}{ Uncertain } & \multicolumn{2}{|c|}{ Disagree } & \multicolumn{2}{|c|}{$\begin{array}{c}\text { Completely } \\
\text { disagree }\end{array}$} & \multirow[t]{2}{*}{$\mathbf{X}^{2}$} & \multirow[t]{2}{*}{$\begin{array}{c}\mathbf{P} \\
\text { value }\end{array}$} \\
\hline & $\mathbf{N}$ & $\%$ & $\mathbf{N}$ & $\%$ & $\mathbf{N}$ & $\%$ & $\mathbf{N}$ & $\%$ & $\mathbf{N}$ & $\%$ & $\mathbf{N}$ & $\%$ & $\mathbf{N}$ & $\%$ & $\mathbf{N}$ & $\%$ & $\mathbf{N}$ & $\%$ & $\mathbf{N}$ & $\%$ & & \\
\hline $\begin{array}{l}\text { Changes } \\
\begin{array}{l}\text { adaptations } \\
\text { body }\end{array} \\
\text { pregnancy }\end{array}$ & 0 & 0.0 & 0 & 0.0 & 80 & 88.9 & 6 & 6.7 & 4 & 4.4 & 77 & 85.6 & 3 & 3.3 & 10 & 11.1 & 0 & 0.0 & 0 & 0.0 & $144.44 *$ & $<0.001$ \\
\hline $\begin{array}{ll}\text { The } & \text { fetus } \\
\text { development }\end{array}$ & 0 & 0.0 & 0 & 0.0 & 77 & 85.6 & 6 & 6.7 & 7 & 7.8 & 80 & 88.9 & 10 & 11.1 & 0 & 0.0 & 0 & 0.0 & 0 & 0.0 & $180.00 *$ & $<0.001$ \\
\hline Pregnancy care & 0 & 0.0 & 5 & 5.6 & 78 & 86.7 & 2 & 2.2 & 5 & 5.6 & 79 & 87.8 & 10 & 11.1 & 1 & 1.1 & 0 & 0.0 & 0 & 0.0 & $162.71 *$ & $<0.001$ \\
\hline Tests & 0 & 0.0 & 10 & 11.1 & 60 & 66.7 & 7 & 7.8 & 13 & 14.4 & 88 & 97.8 & 2 & 2.2 & 0 & 0.0 & 0 & 0.0 & 0 & 0.0 & $173.33 *$ & $<0.001$ \\
\hline Vaccinations & 0 & 0.0 & 20 & 22.2 & 12 & 13.3 & 8 & 8.9 & 50 & 55.6 & 90 & 100 & 0 & 0.0 & 0 & 0.0 & 0 & 0.0 & 0 & 0.0 & $180.00^{*}$ & $<0.001$ \\
\hline Nutrition & 5 & 5.6 & 23 & 25.6 & 54 & 60.0 & 7 & 7.8 & 1 & 1.1 & 0 & 0.0 & 87 & 96.7 & 3 & 3.3 & 0 & 0.0 & 0 & 0.0 & $95.868 *$ & $<0.001$ \\
\hline Taking supplements & 0 & 0.0 & 15 & 16.7 & 43 & 47.8 & 7 & 7.8 & 25 & 27.8 & 0 & 0.0 & 85 & 94.4 & 5 & 5.6 & 0 & 0.0 & 0 & 0.0 & $111.08^{*}$ & $<0.001$ \\
\hline Personal hygiene & 30 & 33.3 & 25 & 27.8 & 5 & 5.6 & 29 & 32.2 & 1 & 1.1 & 0 & 0.0 & 90 & 100 & 0 & 0.0 & 0 & 0.0 & 0 & 0.0 & $101.73^{*}$ & $<0.001$ \\
\hline Employment & 0 & 0.0 & 38 & 42.2 & 25 & 27.8 & 22 & 24.4 & 5 & 5.6 & 0 & 0.0 & 85 & 94.4 & 5 & 5.6 & 0 & 0.0 & 0 & 0.0 & $58.293 *$ & $<0.001$ \\
\hline Travel & 64 & 71.1 & 6 & 6.7 & 20 & 22.2 & 0 & 0.0 & 0 & 0.0 & 90 & 100 & 0 & 0.0 & 0 & 0.0 & 0 & 0.0 & 0 & 0.0 & $30.390 *$ & $<0.001$ \\
\hline Rest \& sleep & 45 & 50.0 & 35 & 38.9 & 5 & 5.6 & 5 & 5.6 & 0 & 0.0 & 0 & 0.0 & 89 & 98.9 & 1 & 1.1 & 0 & 0.0 & 0 & 0.0 & $76.183^{*}$ & $<0.001$ \\
\hline Exercise & 0 & 0.0 & 0 & 0.0 & 65 & 72.2 & 15 & 16.7 & 10 & 11.1 & 0 & 0.0 & 67 & 74.4 & 3 & 3.3 & 20 & 22.2 & 0 & 0.0 & $134.24 *$ & $<0.001$ \\
\hline Intercourse & 0 & 0.0 & 0 & 0.0 & 0 & 0.0 & 78 & 86.7 & 12 & 13.3 & 80 & 88.9 & 5 & 5.6 & 5 & 5.6 & 0 & 0.0 & 0 & 0.0 & $180.00 *$ & $<0.001$ \\
\hline Taking medication & 0 & 0.0 & 24 & 26.7 & 16 & 17.8 & 23 & 25.6 & 27 & 30.0 & 0 & 0.0 & 83 & 92.2 & 7 & 7.8 & 0 & 0.0 & 0 & 0.0 & $86.054^{*}$ & $<0.001$ \\
\hline Pregnancy risk factors & 0 & 0.0 & 9 & 10.0 & 11 & 12.2 & 30 & 33.3 & 40 & 44.4 & 87 & 96.7 & 3 & 3.3 & 0 & 0.0 & 0 & 0.0 & 0 & 0.0 & $171.00 *$ & $<0.001$ \\
\hline Vitamin taking & 0 & 0.0 & 23 & 25.6 & 7 & 7.8 & 20 & 22.2 & 40 & 44.4 & 0 & 0.0 & 55 & 61.1 & 15 & 16.7 & 20 & 22.2 & 0 & 0.0 & $56.037^{*}$ & $<0.001$ \\
\hline $\begin{array}{l}\text { Baby position, and } \\
\text { coverage }\end{array}$ & 0 & 0.0 & 21 & 23.3 & 9 & 10.0 & 60 & 66.7 & 0 & 0.0 & 0 & 0.0 & 0 & 0.0 & 0 & 0.0 & 86 & 95.6 & 4 & 4.4 & $38.630 *$ & $<0.001$ \\
\hline $\begin{array}{l}\text { Sigh \& symptom of } \\
\text { abortion }\end{array}$ & 0 & 0.0 & 0 & 0.0 & 90 & 100 & 0 & 0.0 & 0 & 0.0 & 0 & 0.0 & 90 & 100 & 0 & 0.0 & 0 & 0.0 & 0 & 0.0 & $180.00 *$ & $<0.001$ \\
\hline $\begin{array}{l}\text { Sigh \& symptom of } \\
\text { labor }\end{array}$ & 0 & 0.0 & 0 & 0.0 & 10 & 11.1 & 0 & 0.0 & 80 & 88.9 & 0 & 0.0 & 88 & 97.8 & 2 & 2.2 & 0 & 0.0 & 0 & 0.0 & $173.33^{*}$ & $<0.001$ \\
\hline $\begin{array}{l}\begin{array}{l}\text { Expected date of } \\
\text { delivery }\end{array} \\
\end{array}$ & 0 & 0.0 & 13 & 14.4 & 27 & 30.0 & 50 & 55.6 & 0 & 0.0 & 0 & 0.0 & 90 & 100 & 0 & 0.0 & 0 & 0.0 & 0 & 0.0 & $134.56^{*}$ & $<0.001$ \\
\hline
\end{tabular}

* Highly Significant $(p<0.001)$ 
Table (3): Effect of Mobile application on the studied primigraphida women' practice before and after intervention $(\mathbf{n}=90)$

\begin{tabular}{|c|c|c|c|c|c|c|}
\hline \multirow{2}{*}{ Items of practice } & \multicolumn{2}{|c|}{ Pre } & \multicolumn{2}{|c|}{ Post } & \multirow{2}{*}{$\mathbf{X}^{2}$} & \multirow{2}{*}{$P$ value } \\
\hline & $\mathbf{N}$ & $\%$ & $\mathbf{N}$ & $\%$ & & \\
\hline \multicolumn{7}{|l|}{ Weight Management } \\
\hline Appropriate for gestational age & 81 & 90.0 & 88 & 97.8 & \multirow{2}{*}{4.744} & \multirow{2}{*}{$0.0294 *$} \\
\hline Over Wight & 9 & 10.0 & 2 & 2.2 & & \\
\hline \multicolumn{7}{|c|}{ Gestational Diabetes Mellitus Control } \\
\hline Controlled & 70 & 77.8 & 80 & 88.9 & \multirow{2}{*}{4.000} & \multirow[b]{2}{*}{$0.0455^{*}$} \\
\hline Uncontrolled & 20 & 22.2 & 10 & 11.1 & & \\
\hline \multicolumn{7}{|l|}{ Identify Risk Behaviors } \\
\hline Correct answer & 81 & 90.0 & 89 & 98.9 & \multirow{2}{*}{6.776} & \multirow{2}{*}{$0.009 *$} \\
\hline Incorrect & 9 & 10.0 & 1 & 1.1 & & \\
\hline \multicolumn{7}{|c|}{ Know Danger Signs During Pregnancy } \\
\hline Correct answer & 79 & 87.8 & 87 & 96.7 & \multirow{2}{*}{4.957} & \multirow{2}{*}{$0.026^{*}$} \\
\hline Incorrect & 11 & 12.2 & 3 & 3.3 & & \\
\hline \multicolumn{7}{|l|}{ Anemia Controlled } \\
\hline Controlled & 70 & 77.8 & 84 & 93.3 & \multirow{2}{*}{8.811} & \multirow{2}{*}{$0.003^{*}$} \\
\hline Uncontrolled & 20 & 22.2 & 6 & 6.7 & & \\
\hline \multicolumn{7}{|l|}{ Vital Signs/W } \\
\hline Stable & 69 & 76.7 & 82 & 91.1 & \multirow{2}{*}{6.947} & \multirow[b]{2}{*}{$0.008^{*}$} \\
\hline Unstable & 21 & 23.3 & 8 & 8.9 & & \\
\hline \multicolumn{7}{|l|}{ Personal Hygiene } \\
\hline Good & 86 & 95.6 & 89 & 98.9 & \multirow{2}{*}{4.709} & \multirow{2}{*}{$0.030^{*}$} \\
\hline $\mathrm{Bad}$ & 4 & 4.4 & 1 & 1.1 & & \\
\hline \multicolumn{7}{|c|}{ Fetus Development Corresponding } \\
\hline Appropriate for Gestational Age & 88 & $\begin{array}{c}97.8 \\
27\end{array}$ & 90 & $\begin{array}{c}100.0 \\
0.0\end{array}$ & \multirow[t]{2}{*}{20.225} & \multirow[t]{2}{*}{$<0.001$} \\
\hline Small for Gestational Age & 2 & 2.2 & 0 & 0.0 & & \\
\hline
\end{tabular}

* statistical significant difference

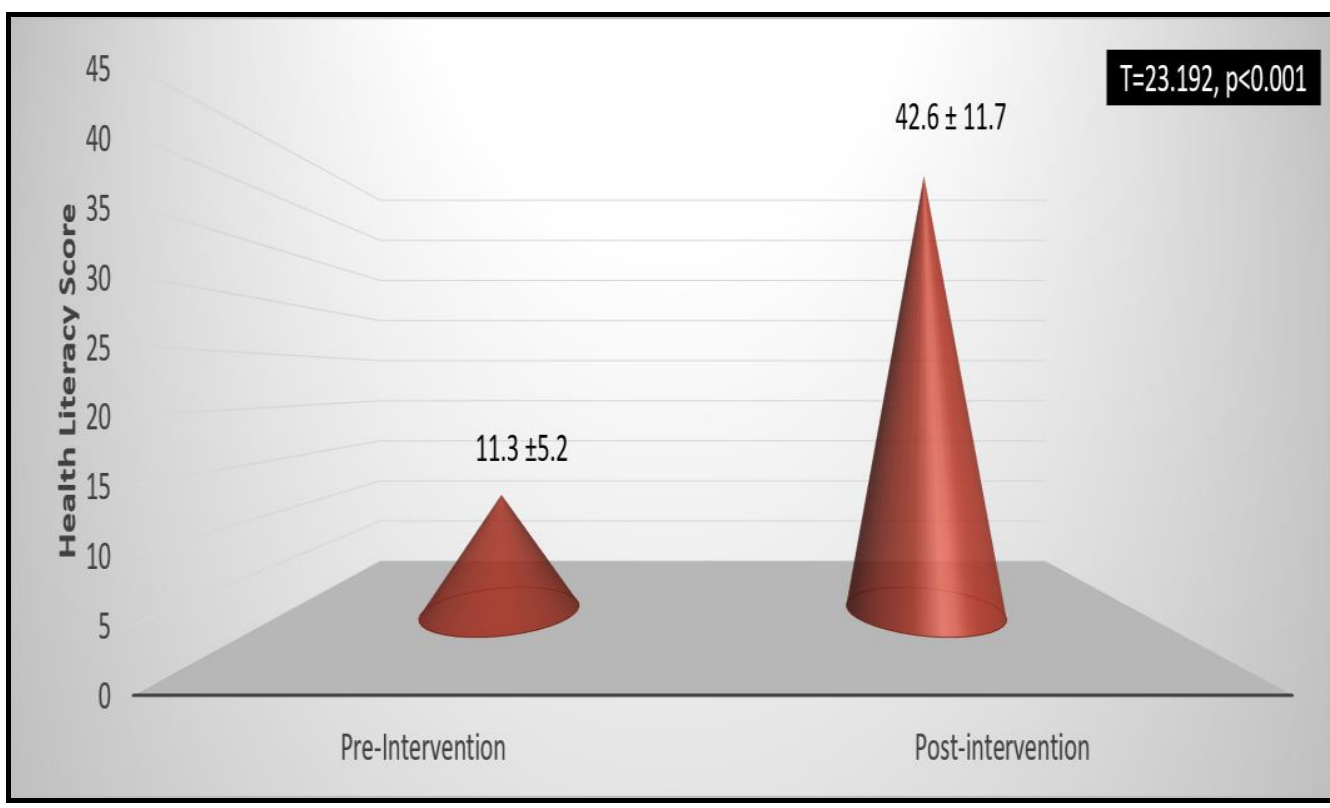

Figure (3): Comparison of the total mean score of health literacy regarding antenatal care among the studied primigraphida women before and after the intervention 


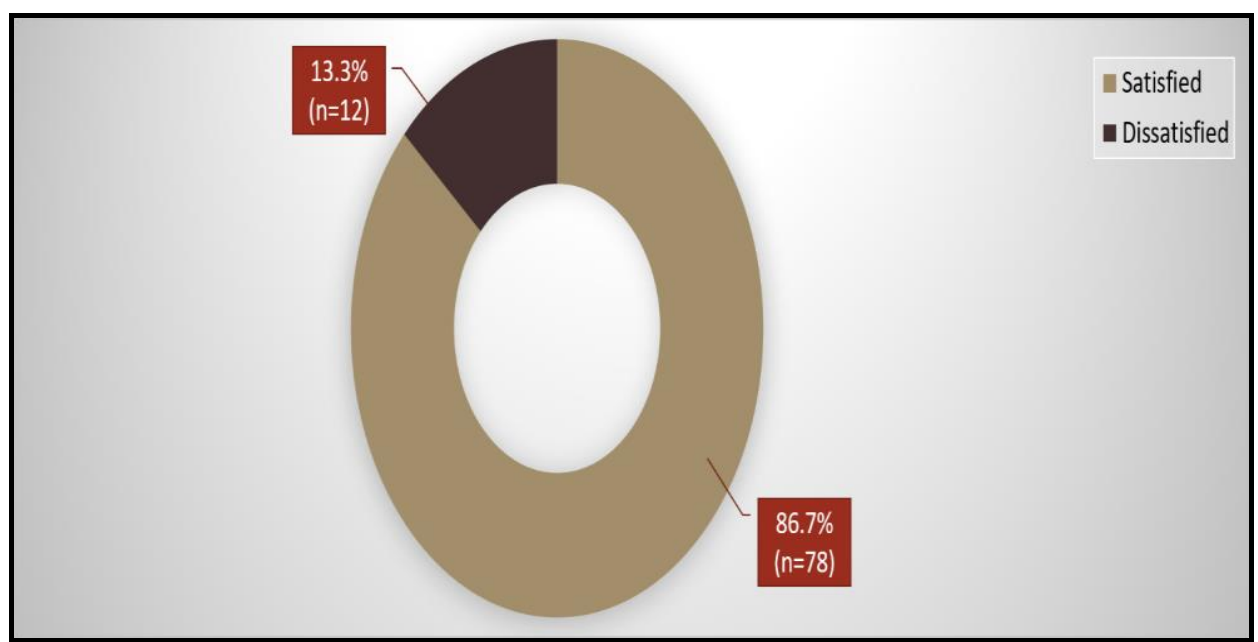

\section{Figure (4): Distribution of satisfaction level toward using of mobile app intervention among the studied primigraphida women}

Table (1): Displayed socio-demographic characteristics of primigraphida women, the mean \pm SD of age per years of the studied women were $(29.2 \pm 6.3)$. Nearly more than three quarters $(77.8 \%)$ of participants were had high education, more than two third of studied participants were working women $(68.9 \%)$, also about three quarters of participants $(75.6 \%)$ are living in urban area. According to family income nearly more than three quarters of participants reported insufficient income. Related to participants gestational age (week) result reveled that less than half $(44.4 \%)$ were ranged from 9-10 weeks of gestation.

Table (2): Showed the effect of mobile application on health literacy levels regarding antenatal care among primigraphida women before and after the intervention. It revealed that there was highly statistical significant difference $(p<0.001)$ among primigravida women in health literacy levels pre and post the intervention and all items of the mobile app's antenatal care information.

Table (3): Represented the effect of mobile application on the studied primigraphida women practice before and after intervention. The result reveled statistical significant differences were found between pre and post app use in relation to weight management, GDM, control identify risk behaviors, know danger signs during pregnancy, and anemia controlled, with $\mathrm{p}$ value are $0.0294,0.0455,0.009$, 0.026 respectively.

Figure (3): Demonstrated comparison of the total mean score of health literacy regarding antenatal care among the studied primigraphida women before and after the intervention. It illustrated that total mean score of health litracy pre intervention was $11.3 \pm 5.2$ while after intervention, the total mean score was improved to $42.6 \pm$ 11.7.So, there was highly statistical significant difference between primigravida women health literacy score pre and post the intervention and all items of mobile app's information $((\mathrm{p}<0.001)$

Figure (4): Presented distribution of satisfaction level toward using of mobile application among studied primigraphida women. It reported that there were $86.7 \%$ of primigravida women were satisfied toward using of mobile app's information while only $13.3 \%$ of primigravida were dissatisfied after using mobile app.

\section{Discussion}

Health literacy is considered one of the major elements of well-being which is crucial for improving the social facilities and financial advance of persons. The HL is a developing perception based on the two principles of health and literacy (Bick, Alexander, \& Adam, 2021). The HL of the pregnant women is important in getting correct and timely care throughout the pandemic period, telemedicine and tele-nursing applications have been used to meet the need for the healthcare throughout the world (Nanda et al., 2020). Particularly during pregnancy, mobile health app has been created and widely used (Blitz et al., 2020). The present study aimed to examine the effect of mobile application intervention on $\mathrm{HL}$ among primigravida during the COVID-19 pandemic. Today, HL documented as an energetic health guide expenses and its absenteeism upsurges the hospitalization rate and medical facilities using because inadequate HL averts appropriate considerate of healthiness communications and data (Tavousi et al., 2020). Mobile applications and social media using has been cumulative in care of pregnancy due to the 
low charge and their simplifying contact nevertheless of time and geographic site in addition the efficacy of technology-based interferences in providing the health care facilities to the pregnant women (Lire, et al., 2021).

Correspondingly, a pretest-posttest of the current study reported that providing data about antenatal care through the mobile application reveled improvement in primigraphida women' knowledge after intervention. Comparable the findings of the current study to the study done by Bonciani et al., (2018). They confirmed this finding and recommended the needing of further research to prove whether the mobile app interventions are effective among pregnant women or not.

Conferring to the outcomes of the current study, the total mean score of HL regarding antenatal care after mobile app using was statistically significant difference $(p<0.001)$; the significant changes show that the mobile app using has been effective in indorsing women HL the findings of current study were reliable with study findings of Kamali et al., (2020) in rapports of changes in HL score pre and post the mobile app using there was a statistically significant difference was presented in the study group $(\mathrm{p}<0.001)$ whereas there was no statistically significant difference was presented in the control group $(p=0.909)$. These findings revealed the importance of HL during pregnancy especially among primigravida women.

In relation to primigraphida women' practice of different health information after app use including weight management, GDM control, anemia control, and knowledge about danger signs during pregnancy in addition fetus development; the current study found that there was a moderate effect in the maternal body weight control and preserving best body composition after using mobile app this may be related to promoting lifestyle change and selfmonitoring based on the information gained from the app. In context of GDM (Tavousi et al., 2020). found that more than half of his study reported GDM control after listening to clinical decisions, cumulative physical activity and altering nutritional consumption due to their engagement in health management program.

The results of the current study displayed that mobile app were also effective for primigravida women with anemia that were more than half have accepted hemoglobin level after app use, similarly Firth et al (2017) appraised that health applications can be utilized in the other health facilities and concluded the positive and important effects establish on lifestyle intervention using the advanced technology is effective in improving the women well-being and reflects positive self-care and good diet habits during pregnancy.

The current study revealed that, through interventions delivered via mobile app also it has been found highly increase in women knowledge about danger signs and symptoms during pregnancy the majority of primigravida women reported correct answer this result provided additional evidence that mobile app can be valuable in increasing pregnancy-related knowledge. In the same context, Redman et al., (2017) stated that mobile applications and social media are becoming progressively widespread among women during pregnancy and their associates to contact health information and acquire to recognize jeopardy activities and pregnancy danger signs.

In the current study almost primigravida women stated that they are completely satisfied with using mobile app and this experience was helpful in gaining right and easy information related to their pregnancy and baby. in addition, use of the mobile app helped in reduce the number of visits to health centers under the conditions of COVID -19. This result was supported by Weigel et al., (2020) who stated that midwives in England informed to endure providing prenatal care and follow up using the mobile web-based technologies. likewise, Bick (2020) reported that the pregnant women who were joining in his study had a positive approach to get the healthcare services via using the mobile app. Providing distance healthcare services via the mobile app during the pandemic is effective to alleviate anxiety of the pregnant women about the failure to deliver health services. So, integrating mobile app into the health system is very important and using them in prenatal care services.

Fortunately, the hypotheses of the current study were accepted. Additionally, as the authors knowledge the topic of effect of mobile application intervention on health literacy regarding among primigravida women during the COVID-19 pandemic was the first study that investigating importance of use the mobile applications in the health care system in Egypt during COVID-19 pandemic.

\section{Conclusion}

The results of the present study declared that mobile app application was effective on improving health literacy regarding antenatal care among primigravida women during the COVID-19 Pandemic. Also, there was highly statistical improvement in total scores of health literacy, primigraphida women, practice and level of satisfaction regarding mobile application intervention in posttest than pre intervention.

\section{Recommendations}

Based on the findings of the current study, the following are recommended: 
1. Utilizing mobile application intervention on health literacy regarding antenatal care among primigravida women during the COVID -19 pandemic by nurses should be encouraged.

2. Efforts should be made by the health professionals, app developers, and ministry of health to ensure quality apps used for providing health promotion information and integrate app in maternal care.

\section{References}

- Ahmed M., Ahmed A., Mohammed A., Saad A., \&, N. (2021): Effect of What Sapp Educational Program Reminder on Pregnant Women's Knowledge, Attitude and Practice Regarding COVID-19 pandemic. Egyptian Journal of Health Care, 12(3), 116-130.

- Bick A, Alexander K \& Adam N. (2021): RealTime Labor Market Estimates During the 2020 Coronavirus Outbreak. Available at SSRN: https://ssrn.com/abstract=3692425 or http://dx .doi.org/10.2139/ssrn.3692425

- Blitz, M., Rochelson, B., Rausch, A., Solmonovich, R., Shan, W., Combs, A., \& Nimaroff, M. (2020): Universal testing for coronavirus disease 2019 in pregnant women admitted for delivery: prevalence of peripartum infection and rate of asymptomatic carriers at four New York hospitals within an integrated healthcare system. American journal of obstetrics \& gynecology MFM, 2(3).

- Bonciani, M., Rosis, S., Vainieri, \& Milena (2018): Promoting the women's health literacy and their access to maternal-care-pathway in Italy through an integrated mHealth intervention. International Journal of Integrated Care (IJIC). Supplement2, Vol. 18, p12. $2 \mathrm{p}$.

- Chan, K., \& Chen, M. (2019): Effects of social media and mobile health apps on pregnancy care: meta-analysis. JMIR mHealth and uHealth, 7(1), e11836.

- Farzi K., Bostani K., \& Niknami M. (2019): Pregnant Women's Health Literacy Promotion Strategies: A Review. Journal of Pharmaceutical Research International.;28(2): 1-8.

- Firth, J., Torous, J., Nicholas, J., Carney, R., Rosenbaum, S., \& Sarris, J. (2017): Can smartphone mental health interventions reduce symptoms of anemia? A meta-analysis of randomized controlled trials. Journal of affective disorders, 218, 15-22.

- Hazari K, Rasha A., Litty P., Nimmi K., Zukaa A., \& Hozaifah M., (2021): Covid-19 infection in pregnant women in Dubai: a case-control study. BMC Pregnancy and Childbirth volume 21, Article number: 658
- Kamali, Z., Abedian, Z., \& Sabermohamad, A. (2020): The Study of health literacy in pregnant women with nausea and vomiting. Journal of health literacy, 2(2), 96-106.

- Karamolahi, P., Khalesi, Z., \& Niknami, M. (2021): Efficacy of Mobile App-Based Training on Health Literacy among Pregnant Women: A Randomized Controlled Trial study.

- Lire, T., Megerssa, B., Asefa, Y., \& Hirigo, A. (2021): Antenatal care service satisfaction and its associated factors among pregnant women in public health centres in Hawassa city, Southern Ethiopia. Proceedings of Singapore Healthcare, 20101058211007881.

- LoBiondo-Wood, G. \& Haber, J. (2018): Nursing research: methods and critical appraisal for evidencebased practice (9th ed.) Elsevier Pp 171-179.

- Melin, J., Bonn, S., Pendrill, L., \& Lagerros, Y., (2020): A questionnaire for assessing user satisfaction with mobile health apps: Development using rasch measurement theory. JMIR mHealth and uHealth, 8(5), e15909.

- Mojoyinola.J. (2011): Influence of maternal health literacy on healthy pregnancy and pregnancy outcomes of women attending public hospitals in Ibadan, Oyo State Nigeria African Res Rev, 5 (3), pp. 28-39

- Mohamed, S., \& Fashafsheh, I. (2019): Effect of Educational Intervention and Telephone Follow-Up Program on Knowledge, Practice and Quality Of Life among Patients with Urinary Diversion: A QuasiExperimental Study. Int J Nurs; 6(1):58-71.

- Musgrave, L., Kizirian, N., Homer, C., \& Gordon, A. (2020): Mobile Phone Apps in Australia for Improving Pregnancy Outcomes: Systematic Search on App Stores. JMIR mHealth and uHealth, 8(11), e22340.

- Nanda, K., Lebetkin, E., Steiner, M., Yacobson, I., \& Dorflinger, L. (2020): Contraception in the era of COVID-19. Global Health: Science and Practice, 8(2), 166-168.

- Nawabi, F., Krebs, F., Vennedey, V., Shukri, A., Lorenz, L., \& Stock, S. (2021). Health Literacy in Pregnant Women: A Systematic Review. International journal of environmental research and public health, 18(7), 3847.

- Özkan S, \&Yaman S. (2018): Use of mobile applications and blogs by pregnant women in Turkey and the impact on adaptation to pregnancy. Midwifery Jul;62:273-277. [doi: 10.1016/j.midw.2018.04.001] [Medline: 29738988]

- Redman, L., Gilmore, L., Breaux, J., Thomas, D., Elkind-Hirsch, K., Stewart, T., \& Martin, C. (2017): Effectiveness of SmartMoms, a novel ehealth intervention for management of gestational weight 
gain: randomized controlled pilot trial. JMIR mHealth and uHealth, 5(9), e8228.

- Santana, S., Brach, C., Harris, L., Ochiai, E., Blakey, C., Bevington, F., \& Pronk, N. (2021): Updating Health Literacy for Healthy People 2030: Defining Its Importance for a New Decade in Public Health. Journal of Public Health Management and Practice.

- Şat, S., \& Sözbir, Ş. (2021): Use of Mobile Applications by Pregnant Women and Levels of Pregnancy Distress During the COVID-19 (Coronavirus) Pandemic. Maternal and Child Health Journal, 1-12.

- Schlottmann, H., Broome, M., Herbst, R., Burkhardt, M.C., \& Mescher, A. (2019): NurseLed Telephone Follow-Up to Improve Parent Promotion of Healthy Behaviors in Young Children With Motivational Interviewing Techniques. J Pediatr Health Care; 33(5):1-10.

- Solhi M., Abbasi K., Ebadi F., \& Hosseini A. (2019): Effect of Health Literacy Education on SelfCare in Pregnant Women: A Randomized Controlled Clinical Trial. IJCBNM.;7(1):2-12. doi: 10.30476/IJCBNM.2019.40841.

- Tavousi, M., Haeri-Mehrizi, A., Rakhshani, F., Rafiefar, S., Soleymanian, A., Sarbandi, F., \& Montazeri, A. (2020): Development and validation of a short and easy-to-use instrument for measuring health literacy: the Health Literacy Instrument for Adults (HELIA). BMC public health, 20, 1-11.

- Weigel, G., Frederiksen, B., \& Ranji, U. (2020): Telemedicine and pregnancy care. Women's Health Policy. Available at: https://www. kf.org/womenshealth-policy/issue-brief/telemedicine-and-pregn ancy-care/ Accessed 16 Dec 2020

- Westwood, A. (2021): Telehealth and maternity. British Journal of Midwifery, 29(6), 352355.

- Whitaker KM., Wilcox S., Liu J, Blair SN., \& Pate RR.(2016): Provider advice and women's intentions to meet weight gain, physicalactivity, and nutrition guidelines during pregnancy. Matern Child Health J;20(11):2309-2317 [FREE Full text] [doi:10.1007/s10995-016-2054-5] [Medline: 27400917]

- Wu, H., Sun, W., Huang, X., Yu, S., Wang, H., Bi, X., \& Ming, W. (2020): Online antenatal care during the COVID-19 pandemic: opportunities and challenges. Journal of medical Internet research, 22(7), e19916. 